\title{
Necessidades dos cuidadores de pacientes vítimas de Acidente Vascular Encefálico após a alta hospitalar*
}

\author{
Fernanda Misawa ${ }^{1}$, \\ Rafaely de Cassia Nogueira Sanches², \\ Anderson da Silva Rêgo ${ }^{3}$, \\ Cremilde Aparecida Trindade Radovanovic ${ }^{4}$
}

\section{RESUMO}

Objetivou-se descrever as necessidades dos cuidadores familiares de pessoas vítimas de acidente vascular encefálico após a alta hospitalar. Pesquisa qualitativa do tipo convergente assistencial, realizada com quatro famílias e operacionalizada por visitas domiciliares de acordo com a necessidade de cada família. Os dados foram coletados por meio de entrevistas abertas e observação participante, transcritos e submetidos à análise de conteúdo, modalidade temática. Os achados foram organizados em duas categorias temáticas, sendo elas: Descobrindo a necessidade de dar continuidade ao tratamento do familiar em casa e; $\mathrm{O}$ apoio social à família no enfrentamento do adoecimento. A partir da realidade observada, foi possível identificar dificuldades e orientar as famílias no domicílio, auxiliando-as em suas adaptações logo após alta hospitalar, além de promover a recuperação da pessoa adoecida e a qualidade de vida do cuidador familiar.

Descritores: Acidente Vascular Cerebral; Relações Familiares; Assistência Domiciliar; Humanização da Assistência; Cuidados de Enfermagem.

\footnotetext{
* Artigo originado da dissertação de mestrado em Enfermagem da Universidade Estadual de Maringá, 2015.

${ }^{1}$ Enfermeira, Mestre em Enfermagem. Maringá, PR, Brasil. E-mail: fermiss@bol.com.br.

2 Enfermeira, Mestre em Enfermagem. Discente do Programa de Pós-Graduação em Enfermagem, nível Doutorado, da Universidade Estadual de Maringá. Professor da Faculdade Alvorada. Maringá, PR, Brasil. E-mail: nogueira sos@hotmail.com.

${ }^{3}$ Enfermeiro, Mestre em Enfermagem. Discente do Programa de Pós-Graduação em Enfermagem, nível Doutorado, da Universidade Estadual de Maringá. Maringá, PR, Brasil. E-mail: anderson0788@hotmail.com.

${ }^{4}$ Enfermeira, Doutora em Ciências da Saúde. Professora Adjunta da Universidade Estadual de Maringá. Maringá, PR, Brasil. E-mail: kikanovick2010@hotmail.com.
}

\section{Como citar esse artigo:}

Misawa F, Sanches RCN, Rêgo AS, Radovanovic CAT. Necessidades dos cuidadores de pacientes vítimas de Acidente Vascular Encefálico após a alta hospitalar. Rev. Eletr. Enf. [Internet]. 2018 [acesso em:

];20:v20a46. Disponível em: https://doi.org/10.5216/ree.v20.47502. 


\section{INTRODUÇÃO}

O Acidente Vascular Encefálico (AVE) é considerado a segunda causa de morte no mundo e gerador de alta carga incapacitante ${ }^{(1-2)}$. As pessoas acometidas, em sua maioria, mesmo após alta hospitalar, apresentam incapacidades funcionais, como ver, sentir, deambular e falar e passam a contar com os cuidados fundamentais assumidos pela família. Representa um impacto socioeconômico sobre a vida familiar e do sistema de saúde ${ }^{(3-6)}$.

Atualmente, existem amplas discussões sobre os avanços necessários para a promoção de estratégias eficazes no processo de reabilitação das pessoas com AVE, principalmente no que tange o retorno ao domicílio(12,5,7). Tais Discussões refletem sobre as redes de apoio social como um recurso valioso para compensar algumas demandas colocadas nos sistemas de saúde ${ }^{(7-8)}$.

No retorno para casa, a perspectiva do cuidado se difere do hospital, uma vez que não há profissionais de saúde para realizá-los no domicílio ${ }^{(9)}$. Porém é crucial que sejam contínuos, a fim de promover a reabilitação e promoção da qualidade de vida das pessoas adoecidas e evitar readmissões hospitalares consideradas potencialmente evitáveis ${ }^{(2,5,10)}$.

Salienta-se ainda que esse momento gera apreensão e medo para as famílias, principalmente nos casos que exigem cuidados mais complexos ${ }^{(7)}$. Por isso é fundamental que as ações de cuidados como, por exemplo, banho no leito, horário das medicações, posições na cama que evitem lesão por pressão, entre outras orientações, sejam passadas para os familiares ainda durante a hospitalização, para que eles possam desenvolvê-los com confiança e qualidade no domicílio(2,10).

Além do treinamento e orientação durante a hospitalização, também é necessário acompanhar as famílias no período de transição da alta hospitalar, a fim de identificar as dificuldades vivenciadas nesse processo e construir junto com elas, estratégias de apoio que amenizem e/ou minimizem o sofrimento familiar ${ }^{(1-2,11)}$. Nesta perspectiva, a Pesquisa Convergente Assistencial (PCA) demonstra ser uma metodologia condizente para conhecer as dificuldades, promover o apoio às famílias que vivenciam essa experiência ao mesmo tempo em que produz dados para investigação(12-14).

Sendo assim, o objetivo deste estudo foi descrever as necessidades dos cuidadores familiares de pessoas vítimas de acidente vascular encefálico após a alta hospitalar.

\section{MÉTODO}

Estudo exploratório, descritivo de abordagem qualitativa, do tipo Convergente Assistencial (PCA) junto a cuidadores de pessoas vítimas de AVE logo após a alta hospitalar. A principal justificativa para a escolha da PCA é devido sua possibilidade de articulação com a prática assistencial de enfermagem, permitindo a introdução de inovações no cuidado e na formulação de temas de investigação a partir da necessidade emergida do contexto atual para a prática ${ }^{(13-14)}$.

Para a busca e abordagem das famílias foram selecionadas duas instituições hospitalares as quais aprovaram a abordagem das famílias. Um hospital possui 123 leitos, é credenciado ao Sistema Único de Saúde (SUS), caracterizando-se como instituição de caráter público e prioriza atividades de assistência, ensino e pesquisa. A outra instituição atende tanto pelo SUS como convênio e particular, possui uma estrutura atual de atendimento com 192 leitos. 
Os critérios de inclusão adotados para as famílias foram: residir com o familiar adoecido na cidade de Maringá e/ou região metropolitana e exercer o papel de cuidador(es) familiar(es) principal sem receber gratificações financeiras. O conceito de cuidador principal utilizado neste estudo refere-se aquela pessoa responsável em realizar a assistência e os cuidados cotidianos no domicilio ao membro familiar adoecido(8).

Para a pessoa com AVE: ter sido acometida pelo AVE pela primeira vez, internada pelo SUS durante o período de observação das pesquisadoras nas instituições hospitalares; apresentar grau de dependência moderada, severa ou muito severa, identificada a partir da aplicação do Mini Dependence Assessment (MDA) ${ }^{(15)}$.

Os critérios de exclusão foram: pessoa acometida pelo AVE menor de 18 anos, contratação de profissional de saúde e/ou cuidador formal para o desenvolvimento do cuidado no domicilio.

A abordagem das famílias ocorreu nos meses de fevereiro a maio de 2014, e o primeiro contato foi realizado ainda durante a internação do familiar nos setores de clínica médica e pronto atendimento das duas instituições. Foram abordadas 22 famílias, destas, 17 não atenderam aos critérios de inclusão, sendo: (9) por não residir em Maringá e região metropolitana; (3) não atingiram o grau mínimo de dependência de acordo com a avaliação do MDA; (3) por óbito do familiar com AVE; (1) por terem contratado um profissional da saúde para realizar o cuidado no domicilio; (1) por institucionalização em casa de longa permanência do familiar com AVE. Para as cinco famílias que atenderam todos os critérios de inclusão, foram fornecidas informações sobre como se daria a pesquisa e agendado previamente a primeira visita domiciliar seguido à alta hospitalar. Após duas visitas uma família declinou, portanto participaram da pesquisa quatro famílias.

A coleta dos dados ocorreu por meio de visitas domiciliares com frequência mínima de uma visita por semana e duração média de 70 minutos, com total final de 16. Nas visitas sempre estavam presente o cuidador principal e a pessoa acometida pelo AVE. Participaram quatro pessoas adoecidas e seis cuidadores familiares. Os familiares leram e assinaram o Termo de Consentimento Livre e Esclarecido (TCLE) em duas vias. O TCLE da pessoa adoecida foi assinado pelo cuidador principal, ou seja, aquele que assumiu o cuidado diário ao familiar adoecido. Porém, em três famílias as visitas no domicílio também foram consentidas pela pessoa adoecida por meio de autorização verbal, e em uma família o consentimento não foi possível pela gravidade das sequelas decorrentes do AVE.

A assistência de enfermagem foi determinada pelas necessidades emergidas a cada encontro e abrangeu atividades como orientações sobre o cuidado, evolução e complicações da doença, esclarecimentos de dúvidas para todos os membros da família, bem como, demonstração e realização de cuidado direto, como banho no leito e aspersão, higienização da cavidade oral, supervisão da alimentação e curativos, organização de horários de medicações, mudança de decúbito e atividades de entretenimento, com músicas e jogos didáticos.

A assistência de enfermagem teve como base a experiência profissional das enfermeiras integrantes do grupo de pesquisa, bem como, protocolos nacionais sobre Atenção Domiciliar ${ }^{(16)}$, aplicação da Sistematização da Assistência de Enfermagem (SAE) e NANDA, além de estudos teóricos sobre a temática.

Destarte, utilizou-se um diário de campo onde foram registradas as atividades realizadas, dúvidas e necessidades das famílias, entrevistas informais e demais dados provenientes da observação participante. Os encontros com exceção do primeiro foram gravados em aparelho digital após autorização, e posteriormente transcritos na íntegra. Ao final das visitas, as enfermeiras-pesquisadoras realizaram feedback com os participantes. 
As narrativas transcritas, somadas ao diário compuseram o corpus da investigação, o qual foi submetido à análise de conteúdo. Para implementação do processo, seguiu-se as três etapas preconizadas para essa modalidade: a pré-análise, exploração do material e tratamento dos resultados obtidos e interpretados ${ }^{(17)}$.

Da análise emergiram duas categorias: Descobrindo a necessidade de dar continuidade ao tratamento do familiar em casa e $\mathrm{O}$ apoio social à família no enfrentamento do adoecimento. Para garantir o anonimato das famílias, estas foram identificadas com os nomes das quatro estações do ano, sendo utilizado o nome de flores específicas de cada estação para os membros familiares.

O projeto foi aprovado pelo Comitê Permanente de Ética em Pesquisa Envolvendo Seres Humanos da Universidade Estadual de Maringá (Processo no 297.227/2013, CAAE: 16398713.0.0000.0104), atendendo todas as determinações da Resolução 466/12 do Conselho Nacional de Saúde.

\section{RESULTADOS}

Para melhor visualização das características das famílias, construiu-se o Quadro 1 e posteriormente, os resultados discutidos nas duas categorias:

Quadro 1: Caracterização das famílias participantes. Maringá, PR, Brasil, 2015.

\begin{tabular}{|c|c|}
\hline Família & Descrição \\
\hline $\begin{array}{l}\text { Família } \\
\text { Verão }\end{array}$ & $\begin{array}{l}\text { Composta por Amarílis, } 79 \text { anos, professora aposentada, reside com sua filha mais velha, Dália (cuidadora } \\
\text { principal), } 42 \text { anos, funcionária pública, seu genro, Gerânio, } 37 \text { anos, pastor e microempresário, e seus dois } \\
\text { netos, Vinca (10 anos) e Coleus ( } 1 \text { ano e } 7 \text { meses). Amarílis tem Hipertensão Arterial Sistêmica (HAS) e arritmia } \\
\text { cardíaca e após o episódio de AVE apresenta dificuldades de fala, deglutição e deambulação. A família apresenta } \\
\text { uma relação harmoniosa e uma situação financeira estável. }\end{array}$ \\
\hline & $\begin{array}{l}\text { Constituída por Boca-de-leão, } 58 \text { anos, mestre de obras, sua esposa Rosa, } 53 \text { anos, dona de casa, seus dois filhos } \\
\text { e sua neta. Boca-de-leão, após o AVE, apresenta dificuldade de marcha, de fala e perda da memória recente. É } \\
\text { tabagista, tem HAS e doença renal policística grau IV, aguarda para iniciar o tratamento dialítico. Rosa, a } \\
\text { cuidadora principal tem HAS, hipotireoidismo e é tabagista. A família vivencia dificuldades de relacionamento } \\
\text { pelo convívio conflituoso dos dois filhos. O filho Flor-de-maio tem } 26 \text { anos, é usuário de múltiplas drogas. } \\
\text { Orquídea é a filha mais velha, tem } 29 \text { anos, é viúva, tem HAS e síndrome do pânico e tem uma filha de seis anos, } \\
\text { as quais residem no fundo da casa dos pais. }\end{array}$ \\
\hline & $\begin{array}{l}\text { Formada por Azaleia, de } 92 \text { anos, aposentada, sua filha, Cerejeira, de } 58 \text { anos, e seu filho, Jasmim, } 50 \text { anos, } \\
\text { ambos auxiliares de serviços gerais. Ainda no mesmo quintal residem Hortênsia (filha mais velha de Azaleia) e } \\
\text { sua família. Azaleia tem HAS, Alzheimer, sendo que anteriormente ao AVE ela já não deambulava, porém falava e } \\
\text { se alimentava normalmente. Após o evento tornou-se totalmente dependente de cuidados. Jasmim é etilista e } \\
\text { Hortênsia tem diabetes tipo II, HAS, cataratas e necessidades especiais (perna amputada por complicação do } \\
\text { diabetes). As maiores dificuldades apresentadas pela família foram a escassa rede social de apoio. }\end{array}$ \\
\hline $\begin{array}{c}\text { Família } \\
\text { Primavera }\end{array}$ & $\begin{array}{l}\text { É formada por Cravo, } 79 \text { anos, e sua esposa, Gérbera, } 73 \text { anos, ambos aposentados. O casal mora sozinho e tem } \\
\text { sete filhos. A filha mais velha, Calla de } 50 \text { anos, reside com seu esposo e sua filha em uma casa no mesmo } \\
\text { terreno que os pais. As sequelas iniciais do AVE deixaram Cravo com dificuldade de marcha, fala, deglutição, } \\
\text { movimentos do hemicorpo esquerdo. A após quatro semanas de acompanhamento ele começou a demonstrar } \\
\text { melhoras na fala e iniciou o uso de bengalas. Gérbera tem úlcera varicosa em membro inferior direito, sendo } \\
\text { necessária a realização de curativos semanais. As principais dificuldades foram referentes à sobrecarga da } \\
\text { cuidadora, por sua idade e seus problemas circulatórios que dificultam a realização das atividades da vida diária } \\
\text { e consequentemente os cuidados com o marido. }\end{array}$ \\
\hline
\end{tabular}

\section{Descobrindo a necessidade de dar continuidade ao tratamento do familiar em casa}

Ao serem indagadas sobre orientações e treinamento dos profissionais de saúde na alta hospitalar, as famílias referiram terem recebido poucas informações, o que gerou uma série de dúvidas no retorno ao domicílio, entre elas, a preocupação com a reabilitação de seu familiar e as funções comunicativas e motoras perdidas: 
Será que ela vai ficar assim ou vai melhorar com o tempo? (Cerejeira-família inverno). Acho que aos poucos ele vai voltando a andar né? Tem que ter paciência né[...]. (Rosa-família outono).

Além disso, as famílias também relataram sentir insegurança quanto aos horários, doses, reações adversas, indicações e cuidado na administração dos medicamentos prescritos:

Ela está com a pressão alta? Então eu posso dar o remédio agora? Ou espero a hora certa?(Cerejeira-família inverno); Meu marido está com uma coceira horrivel na pele, será que é reação do remédio novo para a pressão que o médico passou? (Rosa-família outono);

Também foi possível observar a preocupação e o medo do cuidador em relação algumas sequelas do AVE, como por exemplo, a disfagia:

Eu dou a alimentação bem amassada, ela não gosta, mas a fonoaudióloga mandou fazer assim, eu fico de olho porque morro de medo que ela engasgue porque ela ainda não consegue engolir direito. (Dália - família verão).

Tem que dar tudo amassadinho, é ordem do médico, se não ele engasga e vai tudo para o pulmão que nem aconteceu no hospital. (Gérbera-família primavera).

Observou-se que os familiares também demonstraram medo em relação ao risco de quedas e em especial durante o banho:

Os meus filhos vêm todo dia a noite para dar banho no pai, eles morrem de medo do pai escorregar, já pensou? Deus me livre se esse homem cai no banheiro e acontece alguma coisa! (Gérbera-família primavera).

O cuidado com a pele também foi um aspecto discutido com as famílias, principalmente com a família inverno na qual Azaleia é acamada e totalmente dependente de cuidado. Diante das lesões por pressão que Azaleia desenvolveu, é possível perceber a angústia e sentimento de impotência por parte da cuidadora:

Eu estou triste de ver minha mãe assim, enquanto ela não tinha essas feridas... até que dava, mas agora está difícil e olha que eu fiz de tudo para isso não acontecer [chorou]. (Cerejeira-família inverno).

Diante das dúvidas, angústias e dificuldades enfrentadas pelos familiares, as enfermeiras-pesquisadoras realizaram orientações sobre as reações adversas das medicações, organizaram os horários marcando em agendas e/ou papéis fixados em pontos visíveis, orientaram sobre técnicas de banho no leito e de aspersão e auxiliaram nos primeiros banhos até que ganhassem confiança para fazê-lo sozinhos. No que tange à alimentação, buscouse orientar as famílias para que tivessem calma e paciência durante as refeições e ofertassem o alimento de acordo com a necessidade, velocidade de mastigação e deglutição do membro adoecido. Em alguns momentos, a pessoa adoecida foi estimulada a alimentar-se sozinha.

Em relação ao tratamento das lesões por pressão já instaladas, foi estimulado a manutenção do curativo de hidrocolóide nas regiões calcânea e sacral dos pacientes que já apresentavam hiperemia, com o intuito de evitar a perda da integridade da pele naquelas regiões. Orientou-se sobre a realização de massagens de alívio com soluções oleosas corporais após o banho. 
Além das orientações sobre a manutenção da higiene oral, as pesquisadoras-enfermeiras auxiliaram e demonstraram técnicas de limpeza da cavidade oral. Também foram realizadas atividades para estimulação da cognição, por meio de atividades lúdicas.

\section{O apoio social à família no enfrentamento do adoecimento}

A maioria das famílias possuía algumas relações de apoio, familiar ou da sociedade, que facilitaram o processo de readaptação e cuidado ao familiar adoecido:

Olha não está fácil não, trabalhar e cuidar dela [...] é um corre, corre. Eu tenho que dar o banho nela sozinha, aí depois eu dou a janta e os remédios todos, ainda bem que meus patrões são bons pra mim eles me liberam pra vir ver ela, onde em outro lugar ia dar pra fazer assim? [...] eles me apoiam em tudo que eu preciso é como uma família. (Cerejeirafamília inverno).

Identificou-se que algumas famílias se encontravam em isolamento social, devido a dificuldades de sair de casa por falta de tempo do cuidador para atividades de lazer, ou até mesmo, pelo medo de amigos e familiares em interferir nos cuidados. Todos os cuidadores referiram se sentirem isolados pelas demandas de cuidado ao familiar:

A gente acaba não saindo muito também e como somos novos aqui na cidade não recebemos muitas visitas. (Dália família verão).

Eu não tenho com quem deixar ela por isso eu não saio com minhas amigas. (Cerejeira-família inverno).

Observou-se que as famílias apresentaram dificuldades financeiras, devido ao acentuado aumento dos gastos, bem como, pelo declínio da renda familiar frente à impossibilidade do cuidador em exercer atividades laborais. No entanto, percebeu-se o apoio financeiro e provimento de alimentos de outros atores sociais diretamente envolvidos com as famílias, como a igreja e amigos do comércio, além da renda extra de atividades laborais autônomas, assumidas por outros familiares não envolvidos diretamente com o cuidado cotidiano:

Ele não conseguiu a aposentadoria ainda e a gente está sem renda, os filhos ajudam um pouco, meus irmãos, a gente recebe cesta básica da pastoral, mas eu estou cansada depender dos outros é ruim! (Rosa-família outono). Aumentou os gastos, ainda bem que tem muita gente que me ajuda [...], mas mesmo assim eu preciso comprar algumas coisas 'fiado' na farmácia, eu dou um jeito, mas não deixo ela sem as coisas. (Cerejeira-família inverno).

\section{DISCUSSÃO}

Muitas famílias ao enfrentarem a situação da condição crônica são confrontadas com a escolha de um papel importante e preponderante na recuperação dos seus entes adoecidos: ser cuidador. O cuidado realizado pelos familiares no domicilio está sendo visto pelas políticas públicas de saúde brasileiras como um potente recurso para desospitalização ${ }^{(16)}$. No regresso para a casa após o processo de hospitalização, a família encontra-se frágil e o cuidador familiar é escolhido, o qual assegura a continuidade dos cuidados ${ }^{(18-19)}$.

Muitas vezes esse cuidado é realizado de maneira intuitiva, podendo existir potenciais falhas, decorrentes tanto da ausência de orientações ainda durante a hospitalização, quanto à orientações que não vão ao encontro 
das reais necessidades do cuidador. Além disso, deve-se considerar o pouco tempo que os familiares possuem para se apropriarem das orientações realizadas durante o tempo de internamento( ${ }^{(20)}$.

É preciso salientar a importância da continuidade dos cuidados após a alta hospitalar para obtenção de resultados positivos no tratamento, melhor adaptação e recuperação das limitações provocadas pelo AVE, a fim de evitar comorbidades e consequentemente, internações potencialmente evitáveis ${ }^{(21)}$.

Destarte, a literatura aponta que o evento do AVE na vida da família, gera apreensão em relação à continuidade do cuidado, especialmente quando os cuidadores familiares não são submetidos a um preparo(5,7,18,). Por isso é necessário instrumentalizar e capacitar os familiares ainda na instituição antes da alta hospitalar para promover maior segurança nos cuidados no domicílio(1, 21-22).

A reabilitação da pessoa acometida pelo AVE visa recuperar a independência para o autocuidado e autogestão no domicilio e evitar complicações advindas da diminuição da movimentação corporal e imunidade. Dessa maneira, as ações necessitam envolver orientações que auxiliam na melhor recuperação em todos os sentidos, tanto físico quanto mental, espiritual e social, em busca da recuperação da dignidade, respeito a si próprio e independência ${ }^{(18,22)}$.

Na presente pesquisa a pessoa adoecida foi estimulada a realizar atividades, como escovar os dentes e alimentar-se sozinha, de acordo com seu nível cognitivo e motor. Apreendeu-se que a autonomia, mesmo na realização de atividades simples e cotidianas, conferia autoestima, confiança e bem-estar além de promover a redução da sobrecarga dos cuidadores ${ }^{(5,7,19)}$.

Também foram realizadas orientações sobre as medicações, como mecanismo de ação, horários, doses e reações adversas. Quando se fez necessário, a administração do medicamento foi realizada pelas enfermeiraspesquisadoras. Observou-se nas narrativas das famílias grande insegurança sobre essa temática, e tais dúvidas são atribuídas ao fato do cuidador domiciliar não receber orientações básicas pelos profissionais de saúde ainda no momento da internação hospitalar. Esse fato gera conhecimento inadequado, principalmente pela complexidade das medicações e inquietação sobre o modo de cuidar ${ }^{(10)}$.

Após um AVE cerca de $30 \%$ a $40 \%$ das vítimas requerem algum tipo de auxílio para a alimentação, devido a disfagia. As complicações mais frequentes dos pacientes disfágicos são a pneumonia aspirativa e desnutrição, decorrentes da assinergia do mecanismo de deglutição. A disfagia geralmente está associada com tosse após a deglutição, dificuldade respiratória, infecção pulmonar e compromete tanto a parte respiratória como a nutrição ${ }^{(5,21)}$.

Para as famílias que enfrentavam essa dificuldade, foi realizada orientação para o cuidador familiar manterse calmo a fim de transmitir tranquilidade à pessoa adoecida durante a deglutição. A cada visita e a cada dúvida que surgia dos familiares diante do cuidado, percebia-se que as dificuldades enfrentadas pelos cuidadores estão, em sua maioria, diretamente relacionadas à falta de informações sobre a doença, tratamento e suas complicações.

A preocupação com o risco de queda também foi observada nas quatro famílias. Estudo ${ }^{(20)}$ apresentou como principais fatores de risco para queda, o equilíbrio prejudicado, idade acima de 65 anos, déficit proprioceptivo, força diminuída nas extremidades inferiores, dificuldade de marcha, estado mental rebaixado, dificuldades visuais e uso de anti-hipertensivo. A orientação para o risco de quedas deve fazer parte do 
planejamento dos cuidados à pessoa acometida pelo AVE, afim de que medidas de proteção e prevenção também possam ser implementadas pelos familiares que cuidam.

Apesar de todo o cuidado desempenhado pelo cuidador, não foi possível evitar o desenvolvimento de lesão por pressão, que pode estar relacionado à diminuição da capacidade perceptiva, circulação sanguínea e mobilidade prejudicada ${ }^{(7,20)}$. Orientações específicas como mudança de decúbito, massagens com ácidos graxos essenciais, uso de colchão especializado para reduzir a pressão, promoção da saída da cama e adequada nutrição foram fornecidas com objetivo de melhorar a cicatrização da pele e prevenir o surgimento de outras lesões, bem como contaminação das já existentes.

Além do importante papel dos profissionais nas orientações e treinamentos, destaca-se ainda a importância da rede de apoio social da família, a qual pode ser definida como a trama de relações que envolvem um sujeito, sejam pessoas, instituições ou movimentos sociais ${ }^{(11,19)}$. A incapacidade do familiar adoecido em voltar ao trabalho possui relevância maior; além de ser fonte de recursos financeiros é também suporte para as relações sociais. 0 adoecimento de um familiar é reconhecido como um processo que pode culminar com o empobrecimento da rede social, expondo a pessoa adoecida em situação de vulnerabilidade social ${ }^{(18,20)}$.

Faz-se necessário pontuar que a incapacidade do familiar adoecido em voltar ao trabalho pode determinar redução de sua qualidade de vida e de seus familiares. Nesse sentido, as dificuldades financeiras configuram um problema maior a ser enfrentado pela pessoa adoecida e sua família, uma vez que a presença da doença diretamente aumenta os gastos com medicamentos, insumos e serviços ${ }^{(19)}$.

Por fim, foi possível evidenciar as fragilidades enfrentadas diante da condição crônica. É necessário a formulação e concretização de políticas públicas que promovam maior apoio para a família no enfrentamento do cuidado após alta hospitalar. Acredita-se que o investimento nesse momento da recuperação pode contribuir efetivamente para redução das taxas de re-hospitalizações muitas vezes consideradas evitáveis, diante de um cuidado domiciliar de qualidade.

\section{CONCLUSÃO}

Ao adentrar no lar das famílias, foi possível apreender que o adoecimento crônico provoca mudanças variadas na rotina familiar, ao mesmo tempo em que promove o enfrentamento e adaptação à nova realidade. Compreender a família, vivenciar com ela o retorno ao domicilio após a alta, foi possível levantar e identificar as dificuldades por elas enfrentadas. Dentre essas dificuldades, destaca-se dúvidas sobre administração das medicações e sobre a própria patologia AVE e inseguranças no desenvolvimento dos cuidados cotidianos, como o banho e alimentação.

A partir da realidade observada pelas enfermeiras-pesquisadoras devido à abertura do método PCA, foi possível apoiá-las em suas adaptações, promovendo a recuperação da pessoa adoecida, e a qualidade de vida do cuidador familiar.

A utilização da PCA permitiu a formação do vínculo familiar e a identificação das necessidades da família, nos primeiros meses de cuidado no domicílio ao mesmo tempo em que promoveu uma assistência convergente, construída de acordo com as características socioeconômicas, culturais e contextuais de cada uma. 
Apesar da limitação deste estudo ser o tamanho amostral o qual não produz generalizações, seus resultados são confiáveis, pois o principal objetivo foi conhecer com maior profundidade as necessidades dos cuidadores de pessoas vítimas de AVE possuem para exercer o cuidado no domicilio. Ademais, enfatiza-se a necessidade de outros estudos com diferentes abordagens metodológicas que envolvam a temática, em especial com famílias de pessoas dependentes de cuidados.

\section{REFERÊNCIAS}

1. Toles M, Colón-Emeric C, Naylor MD, Asafu-Adje J, Hanson L. Connect-Home: Transitional Care of Skilled Nursing Facility Patients and their Caregivers. J Am Geriatr Soc [Internet]. 2017 [cited 2018 Dec 31];65(10):2322-8. Available from:

https://doi.org/10.1111/jgs.15015.

2. Vloothuis JD, Mulder M, Veerbeek JM, Konijnenbelt M, Visser-Meily JM, Ket JC, et al. Caregiver-mediated exercises for improving outcomes after stroke. Cochrane Database Syst Rev [Internet]. 2016 [cited 2018 Dec 31];(12):CD011058. Available from:

https://doi.org/10.1002/14651858.CD011058.pub2.

3. Nunes HJM, Queirós PJP. Patient with stroke: hospital discharge planning, functionality and quality of life. Rev Bras Enferm [Internet]. 2017 [cited 2018 Dec 31];70(2):415-23. Available from: https://doi.org/10.1590/0034-7167-2016-0166.

4. Celich KLS, Maschio G, Silva Filho CC, Silva TG, Souza SS. Influence of family support in burden of caregivers of individuals with cerebrovascular accident sequelae. Invest Educ Enferm [Internet]. 2016 [cited 2018 Dec 31];34(3):544-550. Available from:

https://doi.org/10.17533/udea.iee.v34n3a14.

5. Pucciarelli G, Vellone E, Savini S, Simeone S, Ausili D, Alvaro R, et al. Roles of Changing Physical Function and Caregiver Burden on Quality of Life in Stroke: A Longitudinal Dyadic Analysis. Stroke [Internet]. 2017 [cited 2018 Dec 31];48(3):733-9. Available from: https://doi.org/10.1161/STROKEAHA.116.014989.

6. Grochovski CS, Campos R, Lima MCAM. Ações de Controle dos Agravos à Saúde em Indivíduos Acometidos por Acidente Vascular Cerebral. Revista Brasileira de Ciências da Saúde [Internet]. 2015 [cited 2018 Dec 31];19(4):269-76. Available from:

http://www.periodicos.ufpb.br/ojs2/index.php/rbcs/article/download/20311/15101.

7. Kelley DE, Lewis MA, Southwell BG. Perceived support from a caregiver's social ties predicts subsequent care-recipient health. Prev Med Rep [Internet]. 2017 [cited 2018 Dec 31];8:108-11. Available from: https://doi.org/10.1016/i.pmedr.2017.08.001. 8. Ministério da Saúde, Secretaria de Atenção à Saúde, Departamento de Atenção Básica. Diretrizes de atenção à reabilitação da pessoa com acidente vascular cerebral [Internet]. Brasília: Ministério da Saúde, 2013 [cited 2018 Dec 31]. Available from: http://bvsms.saude.gov.br/bvs/publicacoes/diretrizes atencao reabilitacao acidente vascular cerebral.pdf.

9. Saldan GG, Figueiredo FSF, Misawa F, Salci MA, Rêgo AS, Salci MA, Radovanovic CAT. Construção de tecnologia educacional para cuidados domiciliários após acidente vascular encefálico: relato de caso. Revista de Enfermagem UFPE on line [Internet]. 2017 [cited 2018 Dec 31];11(4):1784-93. Available from: https://periodicos.ufpe.br/revistas/revistaenfermagem/article/view/15251. 10. Rodrigues RAP, Marques S, Kusumota L, Santos EB, Fhon JRS, Fabrício-Wehbe SCC. Transition of care for the elderly after cerebrovascular accidents - from hospital to the home. Rev Lat Am Enfermagem [Internet]. 2013 [cited 2018 Dec 31];21(spe):21624. Available from: https://doi.org/10.1590/S0104-11692013000700027.

11. Boger EJ, Demain SH, Latter SM. Stroke self-management: A focus group study to identify the factors influencing selfmanagement following stroke. Int J Nurs Stud [Internet]. 2015 [cited 2018 Dec 31];52(1):175-87. Available from:

https://doi.org/10.1016/j.ijnurstu.2014.05.006.

12. Both JE, Leite MT, Hildebrandt LM, Beuter M, Muller LA, Linck CL. Qualification of the nursing team by means of convergentcare research: contributions to the care of the hospitalized elderly person. Esc Anna Nery - Rev Enferm [Internet]. 2014 [cited 2018 Dec 31];18(3):486-95. Available from: http://www.gnresearch.org/doi/10.5935/1414-8145.20140069.

13. Alvim NAT. Pesquisa Convergente Assistencial Enfermagem - Possibilidades para inovações tecnológicas. Esc Anna Nery - Rev Enferm [Internet]. 2017 [cited 2018 Dec 31];21(2):e20170041. Available from: https://doi.org/10.5935/1414-8145.20170041. 14. Trentini M, Paim L. Pesquisa convergente assistencial: um desenho que une o fazer e o pensar na prática assistencial em saúdeenfermagem. $2^{\text {nd }}$ ed. Florianópolis: Insular; 2004.

15. Benhamou R. Avaliar a dependência dos idosos: proposta de uma escala de avaliação rápida e global. Lisboa: Direcção Geral de Saúde. s.d.

16. Portaria no 963, de 27 de maio de 2013 (BR) [Internet]. Redefine a Atenção Domiciliar no âmbito do Sistema Único de Saúde (SUS). Diário Oficial da União. 28 mai. 2013 [cited 2018 Dec 31]. Available from:

http://bvsms.saude.gov.br/bvs/saudelegis/gm/2013/prt0963_27_05_2013.html.

17. Bardin L. Análise de conteúdo. $3^{\text {rd }}$ ed. Reto LA, Pinheiro A, translator. São Paulo: Ed. 70; 2011. 
18. Meira EC, Reis LA, Gonçalves LHT, Rodrigues VP, Philipp RR. Vivências de mulheres cuidadoras de pessoas idosas dependentes: orientação de gênero para o cuidado. Esc Anna Nery - Rev Enferm [Internet]. 2017 [cited 2018 Dec 31];21(2):e20170046. Available from: https://doi.org/10.5935/1414-8145.20170046.

19. Fernandes SC, Angelo M. Family caregivers: what do they need? An integrative review. Rev Esc Enferm USP [Internet]. 2016 [cited 2018 Dec 31];50(4):675-82. Available from: https://doi.org/10.1590/S0080-623420160000500019.

20. Costa TF, Costa KNFM, Fernandes MGM, Martins KP, Brito SS. Qualidade de vida de cuidadores de indivíduos com acidente vascular encefálico: associação com características e sobrecarga. Rev Esc Enferm USP [Internet]. 2015 [cited 2018 Dec

31];49(2):245-52. Available from: https://doi.org/10.1590/\$0080-623420150000200009.

21. Paiva RS, Valadares GV. Vivenciando o conjunto de circunstâncias que influenciam na significação da alta hospitalar: estudo de enfermagem. Esc Anna Nery - Rev Enferm [Internet]. 2013 [cited 2018 Dec 31];17(2):249-55. Available from:

https://doi.org/10.1590/S1414-81452013000200007.

22. Begum R, Riordan S. Nurses experiences of working in Crisis Resolution Home Treatment Teams with its additional gatekeeping responsibilities. J Psychiatr Ment Health Nurs [Internet]. 2016 [cited 2018 Dec 31];23(1):45-53. Available from:

https://doi.org/10.1111/jpm.12276. 